\author{
K. Rokosz ${ }^{*}$, T. Hryniewicz ${ }^{* *}$ \\ Koszalin University of Technology, Division of Surface Electrochemistry and Engineering, \\ Faculty of Mechanical Engineering, Racławicka 15-17, 75-620 Koszalin, Poland \\ 'rokosz@tu.koszalin.pl, ${ }^{* *}$ Tadeusz.Hryniewicz@,tu.koszalin.pl
}

\title{
Cr/Fe RATIO BY XPS SPECTRA OF MAGNETOELECTROPOLISHED AISI 316L SS USING LINEAR, SHIRLEY AND TOUGAARD METHODS OF BACKGROUND SUBTRACTION
}

\begin{abstract}
In the paper, the analyses of $\mathrm{Fe} 2 \mathrm{p}_{3 / 2}$ and chromium $\mathrm{Cr} 2 \mathrm{p}_{3 / 2}$ XPS spectra with fitting by symmetrical and asymmetrical line shapes as well as using Linear, Shirley and Tougaard Method of Background Subtraction are presented. The calculations are performed on AISI 316L SS biomaterial after magnetoelectropolishing MEP operation. It was found, the chromium-to-iron ratio after magnetoelectropolishing MEP for other analyses could be in the range from 2.2 to 6.2 depending on the line shapes as well as type of backgrounds used to XPS spectra fitting. The most important for comparison the surface layers concerning the $\mathrm{Cr} / \mathrm{Fe}$ ratio is to use the same line shape and backgrounds for all analyses.
\end{abstract}

Keywords: XPS spectra fitting; Linear, Shirley, Tougaard Backgrounds; 316L SS; Magnetoelectropolishing MEP; $\mathrm{Cr} / \mathrm{Fe}$ ratio

\section{INTRODUCTION}

Electrochemical polishing (EP) is a well known surface finishing process developed for both metals and alloys [1-5] for over a century now. After the treatment, smooth, stress-free, and passive surface is usually obtained. Recently the magnetic field has been used to modify the process and enhance the effects of the contact-free treatment under the process named magnetoelectropolishing (MEP) [1, 2, 4, 6-9]; hence the treated surface with the improved passivation as a main effect is achieved. Stainless steels used to be the materials most often undergoing the process of electropolishing [1, 2, 6-10]. In order to verify the degree of passivation Authors accepted the ratio of chromium compounds to iron compounds as an indicator of passive surface, and thus the corrosion resistance. The X-ray photoelectron spectroscopy was used as a research method of surface layers obtained after electrochemical polishing.

The analyses of XPS spectra after electropolishing in the magnetic field were presented in many previous works $[1,8,11]$. In all the papers presented the XPS spectra have been fitted by Gaussian-Lorentzian shape lines and Shirley background type. This paper presents and compares the use of various types of line shapes (symmetric and asymmetric) and 3 back- 
ground types (Linear, Shirley, Tougaard) for fitting iron $\mathrm{Fe} 2 \mathrm{p}_{3 / 2}$ and chromium $\mathrm{Cr} 2 \mathrm{p}_{3 / 2} \mathrm{XPS}$ spectra.

\section{METHOD AND EXPERIMENTAL SET UP}

Stainless steel AISI 316L (S31603, 1.4404) nowadays is used in many sectors of industries because of its good corrosion resistance $[1,10]$. The bulk composition of the steel as measured is shown in Table 1. Second column of the Table 1 presents composition given by the manufacturer [10]. The chromium to iron ratio $(\mathrm{Cr} / \mathrm{Fe})$ of that alloy is amounted to 0.25 . During a variety of mechanical and/or electrochemical polishing operations the surface layer usually changes considerably. After electrochemical polishing that ratio increases minimum over ten times.

Table 1. Chemical composition of AISI 316L SS

\begin{tabular}{|l|c|c|}
\hline \multicolumn{1}{|c|}{ Element } & $\begin{array}{c}\text { Typical } \\
\text { composition, wt\% }\end{array}$ & $\begin{array}{c}\text { Content } \\
\text { as measured, wt\% }\end{array}$ \\
\hline Chromium & $16-18$ & 16.92 \\
\hline Nickel & $10-14$ & 10.38 \\
\hline Manganese & 2 (max) & 1.30 \\
\hline Molybdenum & $2-3$ & 2.01 \\
\hline Nitrogen & 0.1 (max) & 0.04 \\
\hline Carbon & 0.03 (max) & 0.02 \\
\hline Silicon & 0.75 (max) & 0.39 \\
\hline Phosphorus & 0.045 (max) & 0.32 \\
\hline Sulfur & 0.03 (max) & 0.01 \\
\hline Copper & - & 0.28 \\
\hline Vanadium & - & 0.09 \\
\hline Cobalt & - & 0.19 \\
\hline Aluminum & - & 0.01 \\
\hline Iron & Balance & 68.04 \\
\hline
\end{tabular}

The samples for XPS measurements were treated by Magnetoelectropolishing MEP [2, 9] under definite conditions, the magnetic field intensity $B=400 \pm 50 \mathrm{mT}$, and current density $i=200 \pm 20 \mathrm{~A} / \mathrm{dm}^{2}$; after that they were immersed for one year in the Ringer's solution. The polishing was carried out in the electrolyte of temperature of $65^{\circ} \mathrm{C}$, with the temperature control of $\pm 10{ }^{\circ} \mathrm{C}$. For the studies, a proprietary mixed sulfuric/phosphoric acids electrolyte $\mathrm{H}_{3} \mathrm{PO}_{4} / \mathrm{H}_{2} \mathrm{SO}_{4}=1.5$ (and $10 \% \mathrm{H}_{2} \mathrm{O}$ of the whole acids' volume) was used. The electrolytic cell was made of glass, containing up to $500 \mathrm{~cm}^{3}$ of electrolyte.

The XPS experiments were carried out in an ultra-high-vacuum system with a base pressure of about $10^{-8} \mathrm{~Pa}$. The XPS measurements, with the angle of $90^{\circ}$, were performed using a SES2002 electron energy analyzer with a monochromatized Al Ka $(h v=1486.6 \mathrm{eV})$ $\mathrm{X}$-ray source (Gammadata-Scienta). A total resolution of about $0.6 \mathrm{eV}$ was obtained for the presented spectra. In view of optimizing the signal-to-noise ratio, one XPS measurement cycle covered 100 sweeps. For the XPS analyses the CasaXPS 2.3.14 software was used [1114]. The XPS spectra were analysed by using Linear (1), Shirley (2), and Tougaard (3) backgrounds. The linear $(1,4)$, standard Shirley (2-4) background requires also choosing two 
points: one at $\left(E_{\text {right }}, I_{\text {right }}\right)$ and another below at $\left(E_{\text {left }}, I_{\text {left }}\right)$ of the peak. In the range $E_{\text {left }}>E$ $>E_{\text {right }}$ the linear and Shirley backgrounds are equal zero [12-16].

$B(E)=I_{\text {right }} \cdot \frac{E_{\text {left }}-E}{E_{\text {left }}-E_{\text {right }}}+I_{\text {right }} \cdot \frac{E-E_{\text {right }}}{E_{\text {left }}-E_{\text {right }}}$

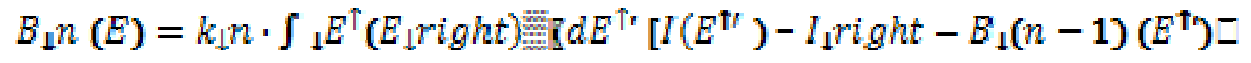

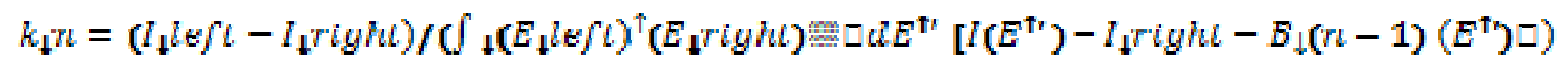

$$
\begin{aligned}
& E_{\text {left }} \leq E \leq E_{\text {right }}
\end{aligned}
$$

where $B_{\mathrm{n}}(E)$ is the $n$-th iteration of the Shirley background, $E$ is the kinetic energy, $k_{\mathrm{n}}$ is the iterative value of the scattering factor, $I(E)$ is the photoelectric signal.

The Tougaard background (5) is computed from the measured spectrum $\mathrm{S}(E)$ using following integral:

$$
B(E)=\int_{E}^{m} F\left(E^{\prime}-E\right) S\left(E^{\prime}\right) d E^{\prime}
$$

For fitting of the XPS spectra the following Gausian-Lorenzian line shapes [13-16] were used, with the respective mathematical formulae shown as equations (6) and (7):

$$
G L(x: E, F, m)=\frac{e^{-4 \ln 2(1-m) \cdot \frac{(x-E)^{2}}{F^{2}}}}{1+4 m \cdot \frac{(x-E)^{2}}{F^{2}}}
$$

where the FWHM is related to $F$ and position to $E$. In Casa XPS the line GL( $x: E, F$, $m)=\mathrm{GL}(m)$, for $m=0$ represents pure Gaussian one and for $m=100$ just pure Lorentzian. For the $0<m<100$ is obtained mix of the two lines by the formula (6).

The second one (7) is the asymmetric line shape based also on Gausian-Lorenzian shape as:

$$
L A(x, \alpha, \beta, F, E)= \begin{cases}{[L(x, F, E)]^{\alpha},} & \text { for } x \leq E \\ {[L(x, F, E)]^{\beta},} & \text { for } x>E\end{cases}
$$

In Casa XPS, the formula is formatted as $\operatorname{LA}(\alpha, \beta, m)$, where $\alpha \neq \beta$ and $m$ is responsible for the control of the width of a Gaussian convolution. On the basis of the analysis shown in the paper, the authors performed the analyses of the influence of shape lines on the fitting of XPS spectra of $\mathrm{Fe}_{2} \mathrm{p}_{3 / 2}$ and $\mathrm{Cr} 2 \mathrm{p}_{3 / 2}$. For this purpose, fittings were done by $\mathrm{GL}(m=10 k)$, for $k \in N$ and $k<10$, as well as for the metallic part of $\operatorname{LA}(1.2,4.8,3)$ in case of iron and $\operatorname{LA}(1.3,4,5)$ for chromium spectra, respectively [16]. 


\section{RESULTS}

In Figures 1-4, there are shown the results of XPS spectra fitted by the symmetrical and asymmetrical shapes lines and after using Shirley method of background subtraction. The next four Figures 5-8 present the fitting results with linear background subtraction. The same analyses with Tougaard background are presented in Figures 9-12. In all these analyses were used the line shapes GL(30) for chromium and iron metal and compounds as well as $\mathrm{LA}(1.3,4,5)$ for chromium metal and $\mathrm{LA}(1.2,4.8,3)$ for iron metal fitting combined with GL(30) for chromium and iron compounds.

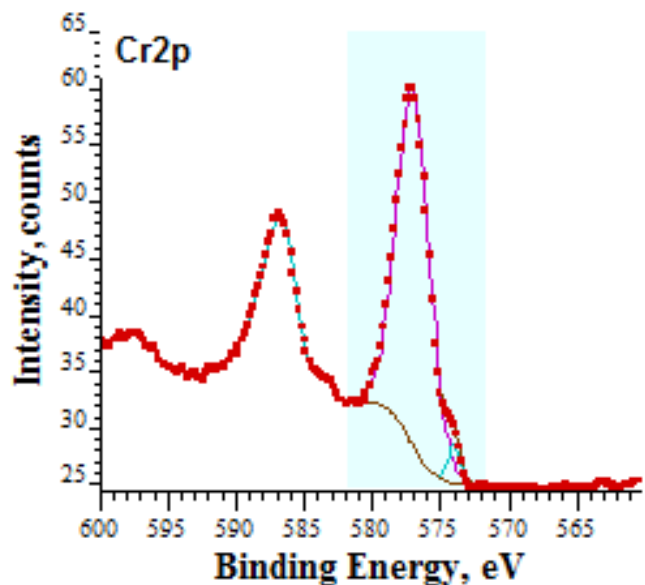

Fig. 1. XPS spectrum analysis of $\mathrm{Cr} 2 \mathrm{p}$ using Shirley method of background subtraction and $\mathrm{GL}(30)$ peak shape lines

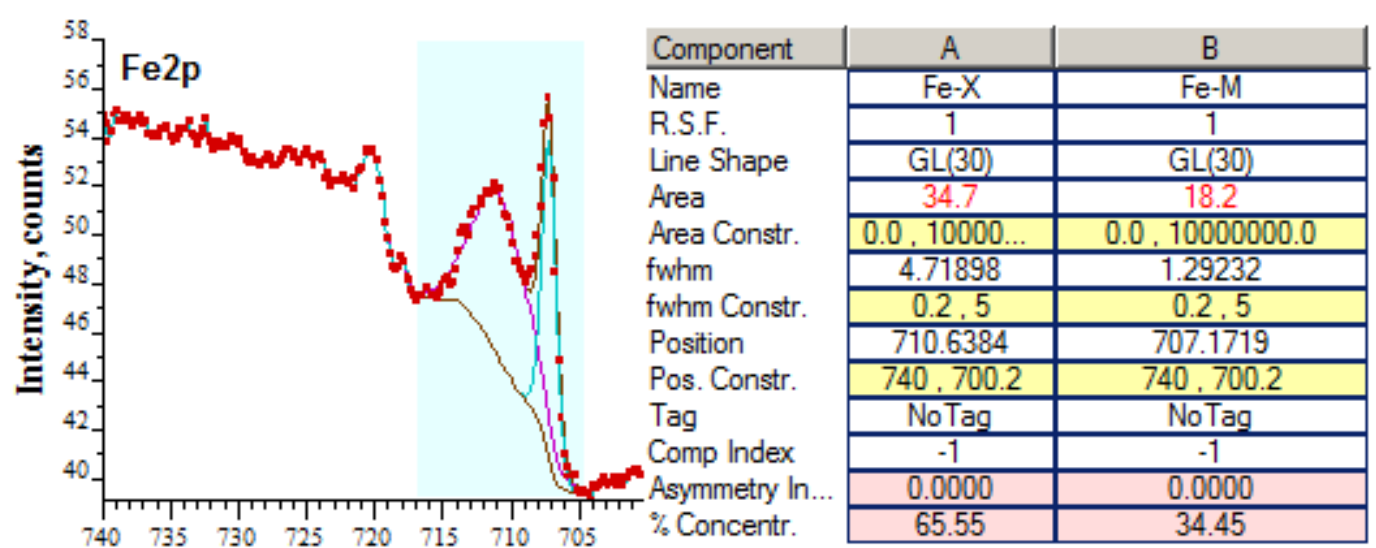

Binding Energy, eV 65.55

\begin{tabular}{l|c|c|} 
Component & $\mathrm{A}$ & $\mathrm{B}$ \\
\hline Name & $\mathrm{Cr}-\mathrm{X}$ & $\mathrm{Cr}-\mathrm{M}$ \\
\cline { 2 - 3 } R.S.F. & 1 & 1 \\
\cline { 2 - 3 } Line Shape & $\mathrm{GL}(30)$ & $\mathrm{GL}(30)$ \\
\cline { 2 - 3 } Area & 97.0 & 3.7 \\
\cline { 2 - 3 } Area Constr. & $0.0,1000000 . \ldots$ & $0.0,10000000.0$ \\
\cline { 2 - 3 } fwhm & 2.83988 & 0.931069 \\
\cline { 2 - 3 } fwhm Constr. & $0.2,5$ & $0.3943,9.857$ \\
\cline { 2 - 3 } Position & 577.0213 & 573.9899 \\
\cline { 2 - 3 } Pos. Constr. & $600,560.2$ & $600,560.2$ \\
\cline { 2 - 3 } Tag & NoTag & NoTag \\
\cline { 2 - 3 } Comp Index & -1 & -1 \\
\cline { 2 - 3 } Asymmetry Index & 0.0000 & 0.0000 \\
\cline { 2 - 3 } \% Concentr. & 96.33 & 3.67 \\
\cline { 2 - 3 } & & \\
\cline { 2 - 3 } & &
\end{tabular}

Fig. 2. XPS spectrum analysis of Fe2p using Shirley method of background subtraction and $\mathrm{GL}(30)$ peak shape lines 


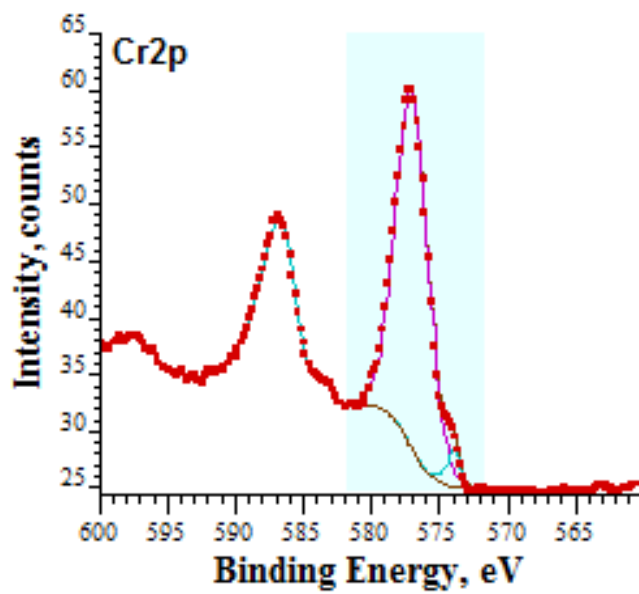

\begin{tabular}{l|c|c|} 
Component & $\mathrm{A}$ & $\mathrm{B}$ \\
\hline Name & $\mathrm{Cr}-\mathrm{X}$ & $\mathrm{Cr}-\mathrm{M}$ \\
\cline { 2 - 3 } R.S.F. & 1 & 1 \\
\cline { 2 - 3 } Line Shape & $\mathrm{GL}(30)$ & $\mathrm{LA}(1.3,4,5)$ \\
\cline { 2 - 3 } Area & 96.3 & 4.3 \\
\cline { 2 - 3 } Area Constr. & $0.0,10000 \ldots$ & $0.0,10000000.0$ \\
\cline { 2 - 3 } fwhm & 2.82315 & 0.640509 \\
\cline { 2 - 3 } fwhm Constr. & $0.2,5$ & $0.3943,9.857$ \\
\cline { 2 - 3 } Position & 577.0290 & 573.8295 \\
\cline { 2 - 3 } Pos. Constr. & $600,560.2$ & 600.560 .2 \\
\cline { 2 - 3 } Tag & NoTag & NoTag \\
\cline { 2 - 3 } Comp Index & -1 & -1 \\
\cline { 2 - 3 } Asymmetry In... & 0.0000 & 0.4539 \\
\cline { 2 - 3 } \% Concentr. & 95.70 & 4.30 \\
\cline { 2 - 3 } & &
\end{tabular}

Fig. 3. XPS spectrum analysis of $\mathrm{Cr} 2 \mathrm{p}$ using Shirley method of background subtraction and $G L(30)$ plus $\operatorname{LA}(1.3,4,5)$ peak shape lines

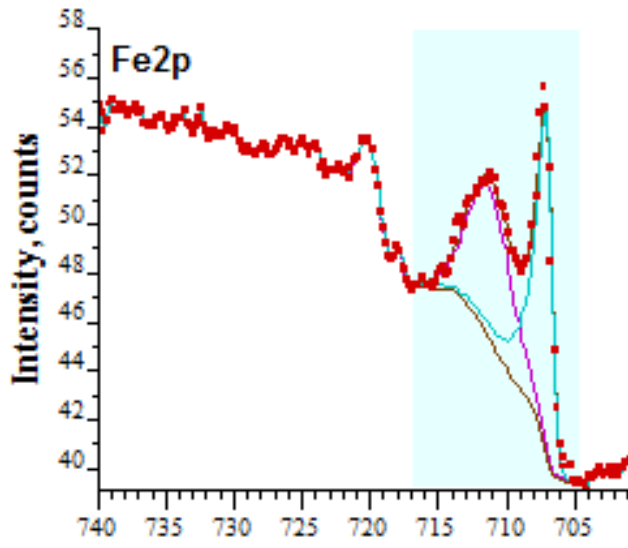

\begin{tabular}{l|c|c|} 
Component & $\mathrm{A}$ & $\mathrm{B}$ \\
\hline Name & $\mathrm{Fe}-\mathrm{X}$ & $\mathrm{Fe}-\mathrm{M}$ \\
\cline { 2 - 3 } R.S.F. & 1 & 1 \\
\cline { 2 - 3 } Line Shape & $\mathrm{GL}(30)$ & $\mathrm{LA}(1.2,4.8,3)$ \\
\cline { 2 - 3 } Area & 25.2 & 27.3 \\
\cline { 2 - 3 } Area Constr. & $0.0,10000 \ldots$ & $0.0,10000000.0$ \\
\cline { 2 - 3 } fwhm & 3.78911 & 0.926369 \\
\cline { 2 - 3 } fwhm Constr. & $0.2,5$ & $0.2,5$ \\
\cline { 2 - 3 } Position & 711.1516 & 706.9765 \\
\cline { 2 - 3 } Pos. Constr. & $740,700.2$ & $740,700.2$ \\
\cline { 2 - 3 } Tag & NoTag & NoTag \\
\cline { 2 - 3 } Comp Index & -1 & -1 \\
\cline { 2 - 3 } Asymmetry In... & 0.0000 & 0.5292 \\
\cline { 2 - 3 } \% Concentr. & 48.02 & 51.98 \\
\cline { 2 - 3 } & &
\end{tabular}

Binding Energy, eV

Fig. 4. XPS spectrum analysis of Fe2p using Shirley method of background subtraction and $G L(30)$ plus $L A(1.2,4.8,3)$ peak shape lines

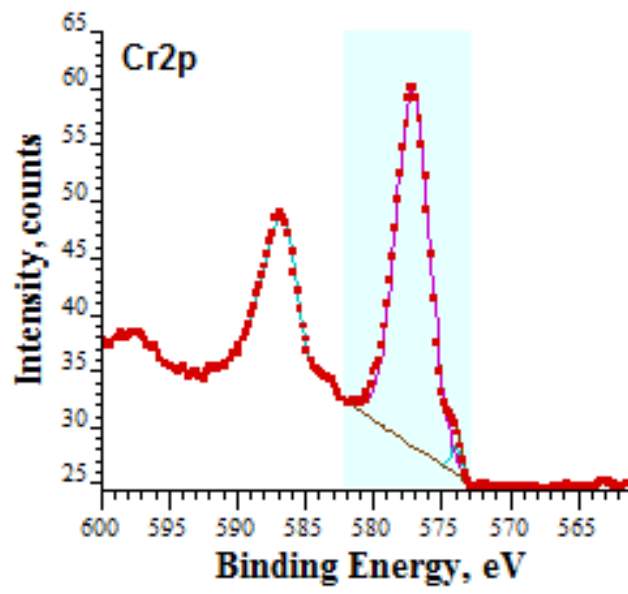

\begin{tabular}{l|c|c} 
Component & $\mathrm{A}$ & $\mathrm{B}$ \\
\hline Name & $\mathrm{Cr}-\mathrm{X}$ & $\mathrm{Cr}-\mathrm{M}$ \\
\cline { 2 - 3 } R.S.F. & 1 & 1 \\
\cline { 2 - 3 } Line Shape & $\mathrm{GL}(30)$ & $\mathrm{GL}(30)$ \\
\cline { 2 - 3 } Area & 100.4 & 2.6 \\
\cline { 2 - 3 } Area Constr. & $0.0,10000 \ldots$ & $0.0,10000000.0$ \\
\cline { 2 - 3 } fwhm & 2.93675 & 0.815578 \\
\cline { 2 - 3 } fwhm Constr. & $0.2,5$ & $0.3943,9.857$ \\
\cline { 2 - 3 } Position & 577.1291 & 573.9501 \\
\cline { 2 - 3 } Pos. Constr. & $600,560.2$ & $600,560.2$ \\
\cline { 2 - 3 } Tag & $\mathrm{NoTag}$ & $\mathrm{NoTag}$ \\
\cline { 2 - 3 } Comp Index & -1 & -1 \\
\cline { 2 - 3 } Asymmetry ln... & 0.0000 & 0.0000 \\
\cline { 2 - 3 } \% Concentr. & 97.50 & 2.50 \\
\cline { 2 - 3 } & &
\end{tabular}

Fig. 5. XPS spectrum analysis of Cr2p using linear method of background subtraction and GL(30) peak shape lines 


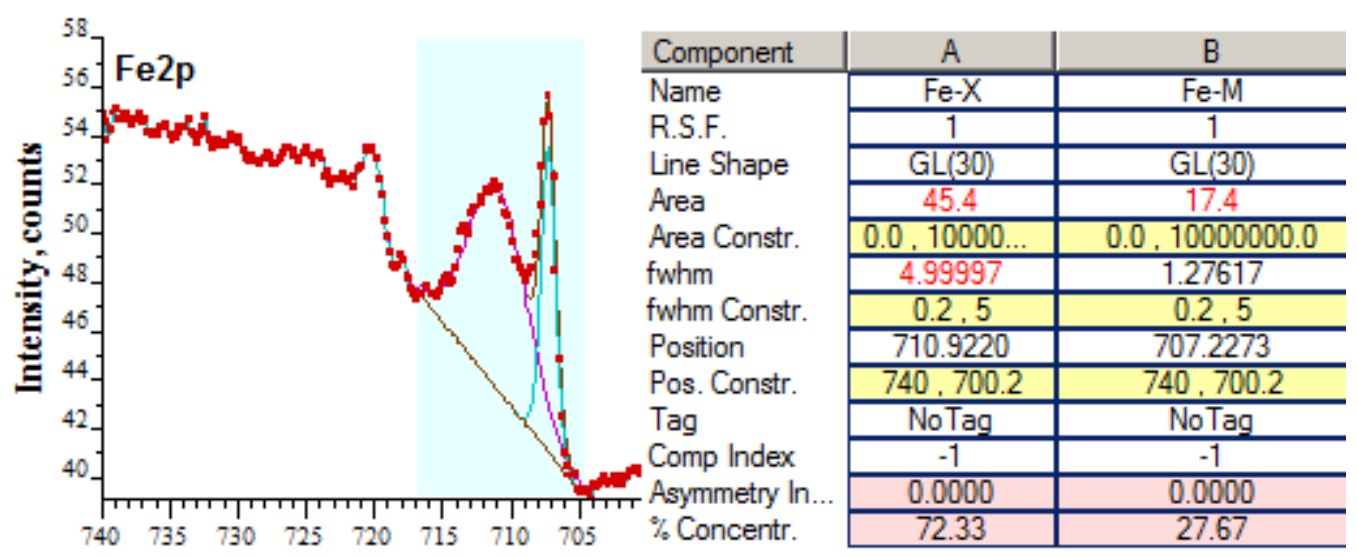

Binding Energy, eV

Fig. 6. XPS spectrum analysis of Fe2p using linear method of background subtraction and GL(30) peak shape lines

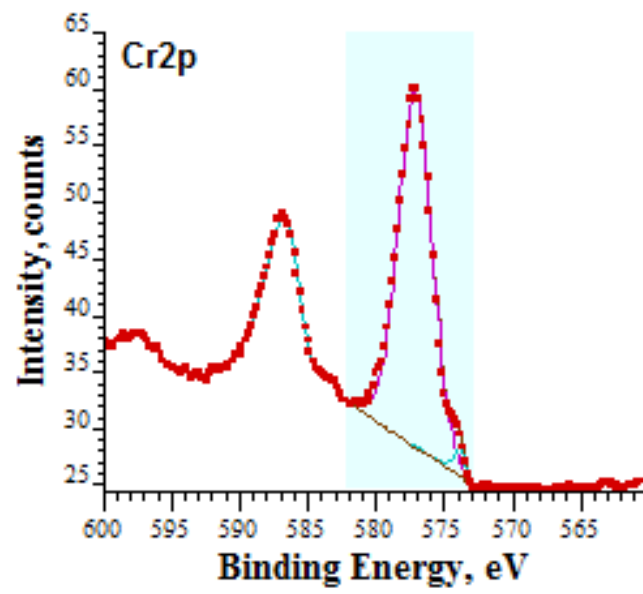

\begin{tabular}{l|c|c|} 
Component & $\mathrm{A}$ & $\mathrm{B}$ \\
\hline Name & $\mathrm{Cr}-\mathrm{X}$ & $\mathrm{Cr}-\mathrm{M}$ \\
\cline { 2 - 3 } R.S.F. & 1 & 1 \\
\cline { 2 - 3 } Line Shape & $\mathrm{GL}(30)$ & $\mathrm{LA}(1.3,4,5)$ \\
\cline { 2 - 3 } Area & 100.0 & 2.8 \\
\cline { 2 - 3 } Area Constr. & $0.0,10000 \ldots$ & $0.0,10000000.0$ \\
\cline { 2 - 3 } fwhm & 2.92798 & 0.519554 \\
\cline { 2 - 3 } fwhm Constr. & $0.2,5$ & $0.3943,9.857$ \\
\cline { 2 - 3 } Position & 577.1325 & 573.7918 \\
\cline { 2 - 3 } Pos. Constr. & $600,560.2$ & $600,560.2$ \\
\cline { 2 - 3 } Tag & NoTag & NoTag \\
\cline { 2 - 3 } Comp Index & -1 & -1 \\
\cline { 2 - 3 } Asymmetry ln... & 0.0000 & 0.4539 \\
\cline { 2 - 3 } \% Concentr. & 97.27 & 2.73 \\
\cline { 2 - 3 } & &
\end{tabular}

Fig. 7. XPS spectrum analysis of Cr2p using linear method of background subtraction and $G L(30)$ plus $L A(1.3,4,5)$ peak shape lines

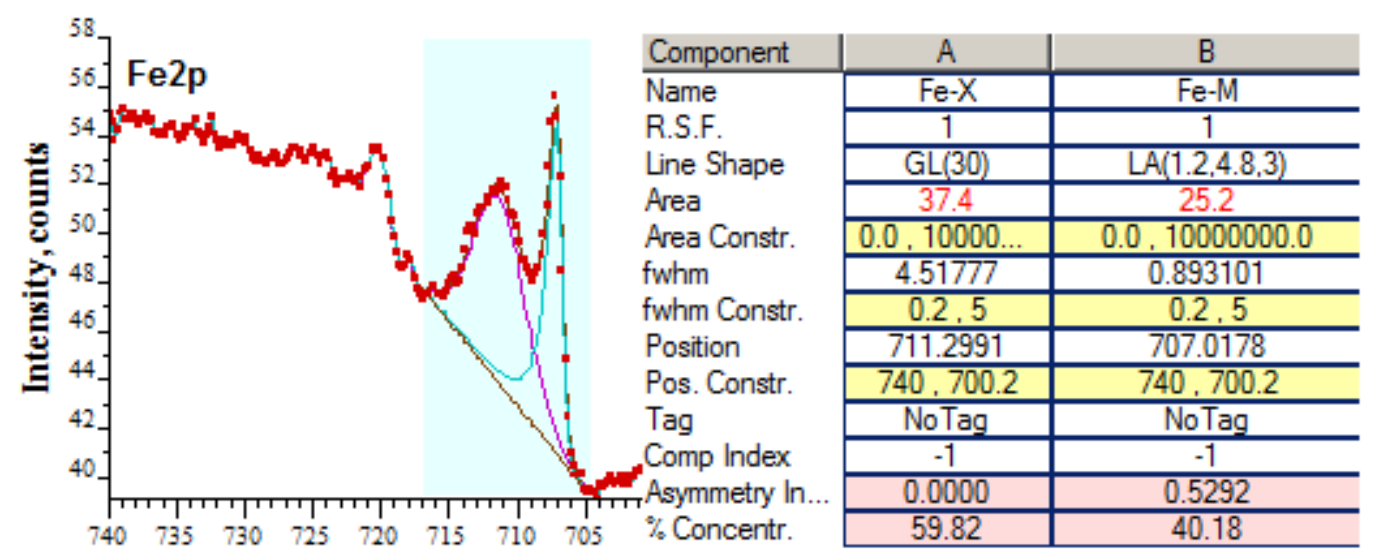

Binding Energy, eV

Fig. 8. XPS spectrum analysis of Fe2p using linear method of background subtraction and $\mathrm{GL}(30)$ plus $\mathrm{LA}(1.2,4.8,3)$ peak shape lines 


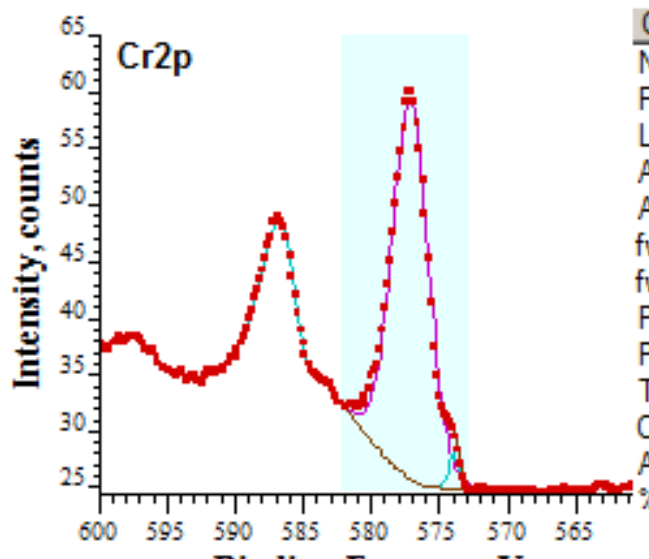

Binding Energy, eV

\begin{tabular}{l|c|c} 
Component & $\mathrm{A}$ & $\mathrm{B}$ \\
\hline Name & $\mathrm{Cr}-\mathrm{X}$ & $\mathrm{Cr}-\mathrm{M}$ \\
\cline { 2 - 3 } R.S.F. & 1 & 1 \\
\cline { 2 - 3 } Line Shape & $\mathrm{GL}(30)$ & $\mathrm{GL}(30)$ \\
\cline { 2 - 3 } Area & 114.4 & 2.8 \\
\cline { 2 - 3 } Area Constr. & $0.0,10000 \ldots$ & $0.0,10000000.0$ \\
\cline { 2 - 3 } fwhm & 3.11689 & 0.819656 \\
\cline { 2 - 3 } fwhm Constr. & $0.2,5$ & $0.3943,9.857$ \\
\cline { 2 - 3 } Position & 577.1440 & 573.9506 \\
\cline { 2 - 3 } Pos. Constr. & $600,560.2$ & $600,560.2$ \\
\cline { 2 - 3 } Tag & $\mathrm{NoTag}$ & $\mathrm{NoTag}$ \\
\cline { 2 - 3 } Comp Index & -1 & -1 \\
\cline { 2 - 3 } Asymmetry In... & 0.0000 & 0.0000 \\
\cline { 2 - 3 } & 97.61 & 2.39 \\
\hline
\end{tabular}

97.61
2.39

Fig. 9. XPS spectrum analysis of Cr2p using Tougaard method of background subtraction and GL(30) peak shape lines

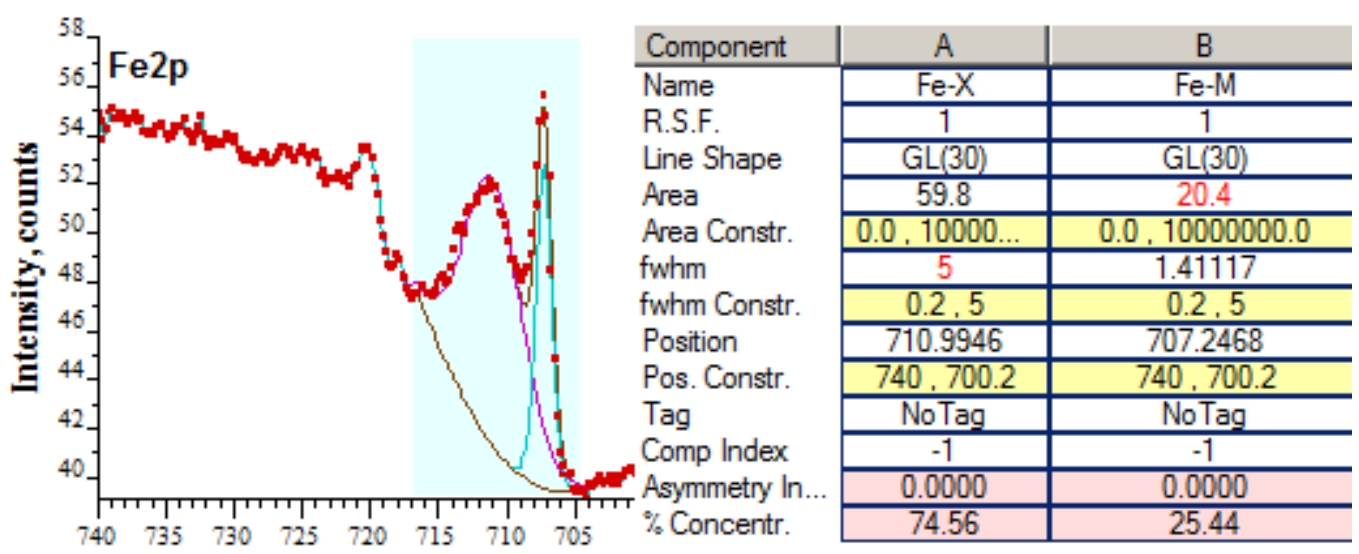

Binding Energy, eV

Fig. 10. XPS spectrum analysis of Fe2p using Tougaard method of background subtraction and GL(30) peak shape lines

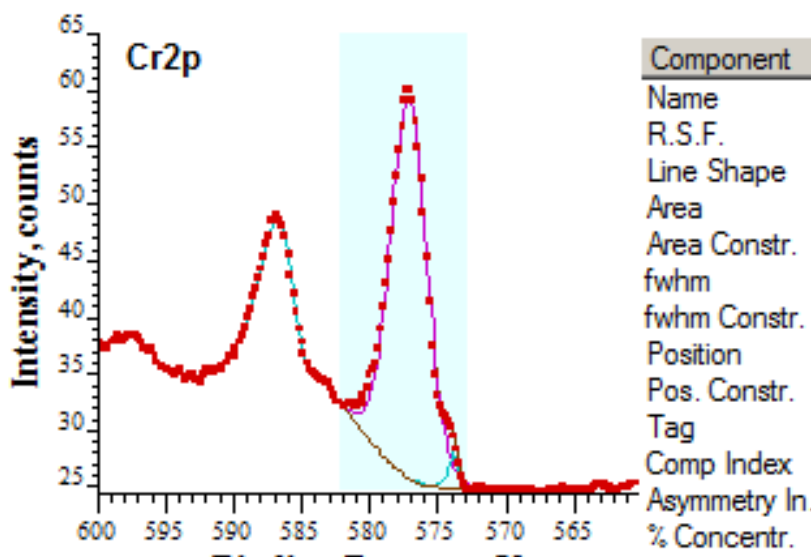

\begin{tabular}{|c|c}
$\mathrm{A}$ & $\mathrm{B}$ \\
\hline $\mathrm{Cr}-\mathrm{X}$ & $\mathrm{Cr}-\mathrm{M}$ \\
\hline 1 & 1 \\
\hline $\mathrm{GL}(30)$ & $\mathrm{LA}(1.3,4,5)$ \\
\hline 114.2 & 3.0 \\
\hline $0.0,10000 \ldots$ & $0.0,10000000.0$ \\
\hline 3.11367 & 0.510261 \\
\hline $0.2,5$ & $0.3943,9.857$ \\
\hline 577.1472 & 573.7848 \\
\hline $600,560.2$ & $600,560.2$ \\
\hline NoTag & NoTag \\
\hline-1 & -1 \\
\hline 0.0000 & 0.4539 \\
\hline 97.48 & 2.52 \\
\hline
\end{tabular}

Binding Energy, eV 
Fig. 11. XPS spectrum analysis of Cr2p using Tougaard method of background subtraction and GL(30) plus $L A(1.3,4,5)$ peak shape lines

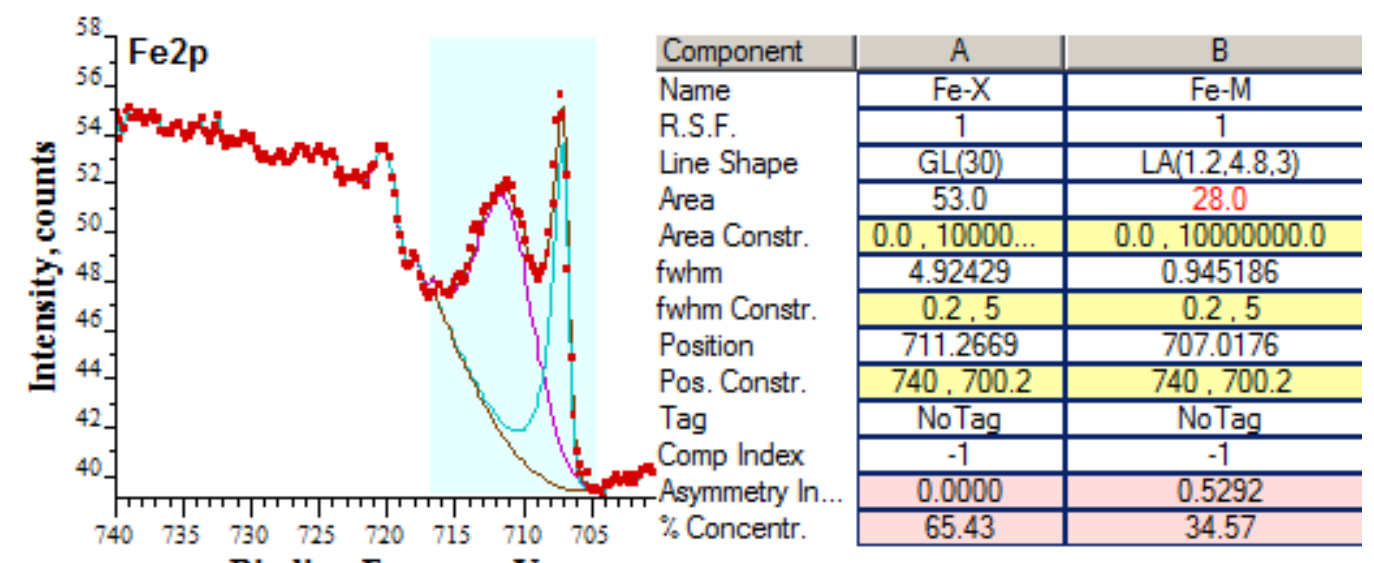

Binding Energy, eV

Fig. 12. XPS spectrum analysis of Fe2p using Tougaard method of background subtraction and GL(30) plus LA $(1.2,4.8,3)$ peak shape lines

In Table 2, there are presented the chromium compounds to iron compounds $\mathrm{Cr} / \mathrm{Fe}$ ratios on the basis of results shown in Figures 1-12. The line shapes in Table 2 refer to the metal part of the fitted spectra. On the basis of the obtained results it is noted that the interval is equal 4. The minimum values of $\mathrm{Cr} / \mathrm{Fe}$ ratio, amounting to 2 , was noted for fitting by GL(30) shape lines for iron metal spectrum parts with Tougaard method of background subtraction. The maximum value was obtained for iron metal shape line LA(1.2,4.8,3) for Shirley method of background subtraction plus for chromium with linear method of background subtraction with using GL(30) or LA $(1.3,4,5)$ line shapes. However, the Authors prefer to use the same methods of background subtraction, which correspond to the results given in bold in Table 2 .

Table 2. Results of Cr/Fe ratio analyses on the basis of results attained of data in Figs. 1-12

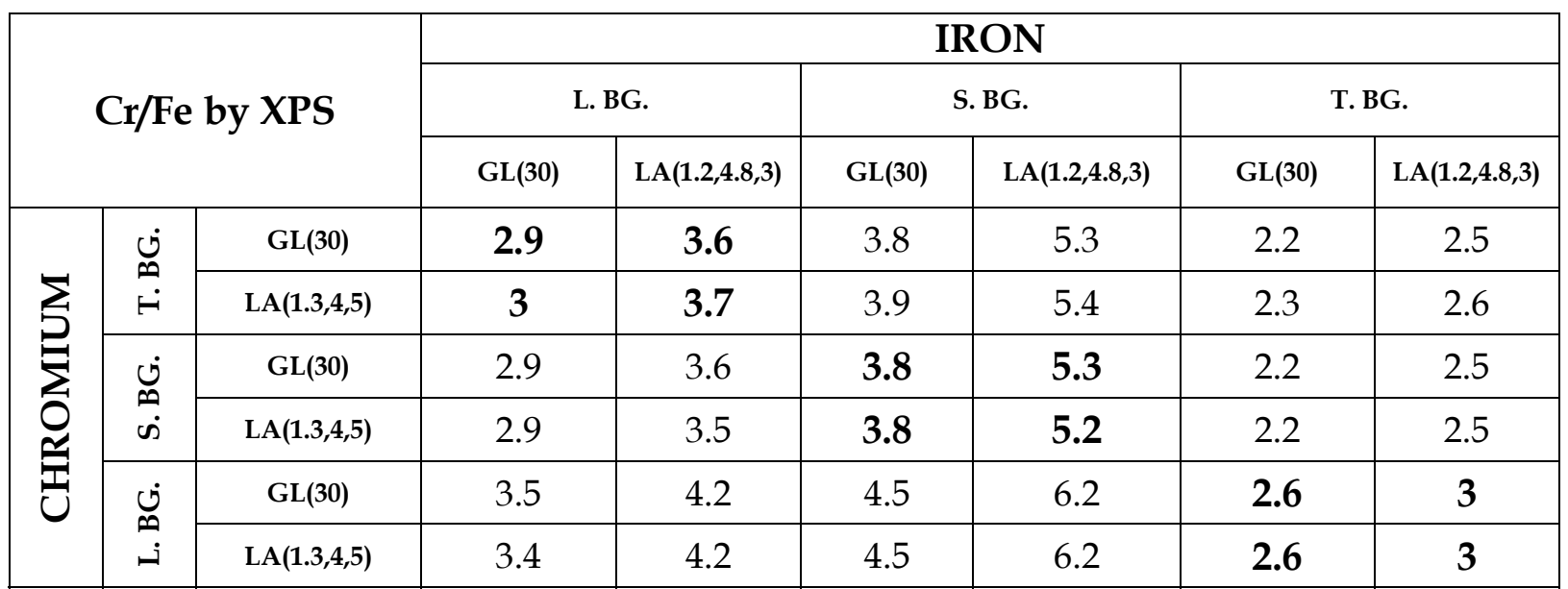

where: L. BG. - Linear Background, S. BG. - Shirley Background, T. BG. - Tougaard Background

On the basis of such restrictions adopted should be noted that the maximum values of chromium compounds to iron compounds is in rage of 2.2 to 5.3. The maximum values were 
obtained for Shirley method of background subtraction and the smallest ones for Tougaard method of background subtraction.

\section{CONCLUSIONS}

Based on the XPS study results and the calculations performed on AISI 316L stainless steel after magnetoelectropolishing (MEP), the following conclusions may be formulated:

(1) Method of background subtraction has a meaningful influence on $\mathrm{Cr} / \mathrm{Fe}$ ratio

(2) Line shape has a significant influence on $\mathrm{Cr} / \mathrm{Fe}$ ratio

(3) Maximum of $\mathrm{Cr} / \mathrm{Fe}$ ratio (equaling 6.2) was obtained for Shirley method of background subtraction in case of iron and for linear method of background subtraction for chromium

(4) Minimum of $\mathrm{Cr} / \mathrm{Fe}$ ratio was obtained for Tougaard method of background subtraction in case of iron and for Tougaard and linear methods of background subtraction for chromium

(5) For the linear method of background subtraction for both iron and chromium the $\mathrm{Cr} / \mathrm{Fe}$ ratio is in the range of 2.9-3.7; average $\mathrm{Cr} / \mathrm{Fe}$ is equal 3.3

(6) For the Shirley method of background subtraction for both iron and chromium the $\mathrm{Cr} / \mathrm{Fe}$ ratio is in the range of 3.8-5.3; average $\mathrm{Cr} / \mathrm{Fe}$ is equal 4.5

(7) For the Tougaard method of background subtraction for both iron and chromium the $\mathrm{Cr} / \mathrm{Fe}$ ratio is in the range of 2.6-3.0; average of $\mathrm{Cr} / \mathrm{Fe}$ is equal 2.8.

\section{ACKNOWLEDGMENT}

Authors of the paper highly appreciate of the XPS apparatus made available by the NTNU Trondheim University, Norway. Special thanks are directed to Professor Steinar Raaen of the Institute of Physics, NTNU Trondheim, for his valuable instructions concerning XPS measurements.

Professor Dr Gregor Mori of the Institute of Schadensanalytik, Montanuniversität Leoben, Austria, is greatly acknowledged for getting chemical analysis of the AISI 316L austenitic stainless steel samples.

\section{REFERENCES}

1. Rokosz K., Polerowanie elektrochemiczne stali w polu magnetycznym (Electrochemical polishing of steels in the magnetic field), Monograph Nr 219, Publisher: Koszalin University of Technology, Koszalin 2012, ISSN 0239-7129, (211 pages, in Polish).

2. Hryniewicz T., Rokicki R., Rokosz K., Magnetoelectropolishing for metal surface modification, Transactions of the Institute of Metal Finishing, 2007, 85(6), 325-332.

3. Hryniewicz T., Concept of microsmoothing in electropolishing process, Surfaceand Coatings Technology, 1994, 64(2), 75-80. 
4. Hryniewicz T., Rokosz K., Polarization Characteristics of Magnetoelectropolishing Stainless Steels, Materials Chemistry and Physics, 2010, 122, 169-174.

5. Simka W., Mosiałek M., Nawrat G., Nowak P., Żak J., Szade J., Winiarski A., Maciej A., SzykWarszyńska L., Electrochemical polishing of Ti-13Nb-13Zr Alloy, Surface and Coatings Technology, 2012, 213, 239-246.

6. Hryniewicz T., Rokicki R., Rokosz K., Surface characterization of AISI 316L biomaterials obtained by electropolishing in a magnetic field, Surface \& Coatings Technology, 2008, 202(9), 1668-1673.

7. Hryniewicz T., Rokosz K., Rokicki R., Electrochemical and XPS Studies of AISI 316L Stainless Steel after Electropolishing in a Magnetic Field, Corrosion Science, 2008, 50(9), 2676-2681.

8. Hryniewicz T., Rokicki R., Rokosz K., Corrosion Characteristics of Medical Grade AISI 316L Stainless Steel Surface after Electropolishing in a Magnetic Field, CORROSION (The Journal of Science and Engineering), Corrosion Science Section, 2008, 64(8), 660-665.

9. Rokicki R., US Patent No 7632390, http://www.patentgenius.com/patent/7632390.html

10. Product Data Bulletin, 316/316L Stainless Steel, AK Steel Corporation, PD-140 7180-0127 PDF 7/00, 2000; www.aksteel.com

11. Hryniewicz T., Rokosz K., Investigation of selected surface properties of AISI 316L SS after magnetoelectropolishing, Materials Chemistry and Physics, 2010, 123, 47-55; DOI:

10.1016/j.matchemphys.2010.03.060

12. Fairley N., http://www.casaxps.com, (C) Casa software Ltd., 2005,

13. Walton J., Carrick A., The Casa Cookbook-The CasaXPS User's Manual, Part 1: Recipes for XPS data proceedings, 2009, ISBN: 9780954953300 , Publisher: Acolyte Science.

14. CasaXPS Processing Software, CasaXPS Manual 2.3.15 Rev 1.0, Copyright (C) 2010 Casa Software Ltd, 19-20.

15. Herrera-Gomez A., The Peak-Shirley Background (Shirley background in overlapping peaks), Centro de Investigación y de Estudios Avanzados del IPN Unidad Querétaro, Internal Report Created 8/2011, Last Update 2/2012, (14 pages).

16. Biesinger M.C., Payne B.P., Grosvenor A. P., Lau L. W. M., Gerson A. R., Smart R. St. C., Resolving surface chemical states in XPS analysis of first row transmission metals, oxides and hydroxides: $\mathrm{Cr}$, Mn, Fe, Co and Ni, Applied Surface Science, 2011, 257, 2717-2730. 